\title{
Poor medication adherence in type 2 diabetes: recognizing the scope of the problem and its key contributors
}

This article was published in the following Dove Press journal:

Patient Preference and Adherence

22 July 2016

Number of times this article has been viewed

\author{
William H Polonsky,2 \\ Robert R Henry ${ }^{2,3}$ \\ 'Behavioral Diabetes Institute, San \\ Diego, ${ }^{2}$ University of California, \\ San Diego, ${ }^{3}$ Center for Metabolic \\ Research, VA San Diego Healthcare \\ System, San Diego, CA, USA
}

\begin{abstract}
At least $45 \%$ of patients with type 2 diabetes (T2D) fail to achieve adequate glycemic control (HbAlc $<7 \%$ ). One of the major contributing factors is poor medication adherence. Poor medication adherence in T2D is well documented to be very common and is associated with inadequate glycemic control; increased morbidity and mortality; and increased costs of outpatient care, emergency room visits, hospitalization, and managing complications of diabetes. Poor medication adherence is linked to key nonpatient factors (eg, lack of integrated care in many health care systems and clinical inertia among health care professionals), patient demographic factors (eg, young age, low education level, and low income level), critical patient beliefs about their medications (eg, perceived treatment inefficacy), and perceived patient burden regarding obtaining and taking their medications (eg, treatment complexity, out-of-pocket costs, and hypoglycemia). Specific barriers to medication adherence in T2D, especially those that are potentially modifiable, need to be more clearly identified; strategies that target poor adherence should focus on reducing medication burden and addressing negative medication beliefs of patients. Solutions to these problems would require behavioral innovations as well as new methods and modes of drug delivery.
\end{abstract}

Keywords: glycemic control, HbAlc, hypoglycemia, medication adherence, psychosocial, type 2 diabetes

\section{Introduction}

The prevalence of type 2 diabetes (T2D) is at epidemic proportions worldwide, ${ }^{1,2}$ and the incidence and prevalence of T2D continue to increase (Figure 1). ${ }^{3,4}$ Indeed, the worldwide prevalence of T2D is expected to increase from 382 million individuals (2013) to 417 million individuals by $2035 .^{1}$ This is of critical concern because T2D represents the largest budget item in many health care systems, ${ }^{5,6}$ primarily due to the high rates of morbidity and mortality associated with the disease. ${ }^{7-9}$ Even worse, it has been well documented that this cost burden has been inexorably growing worldwide. ${ }^{10}$

A key contributor to the remarkably high rates of morbidity and mortality is chronic poor metabolic control, especially poor glycemic control. ${ }^{7}$ Although a wide array of options are now available for treating T2D, including several new pharmacological classes of drugs that are included in the current American Diabetes Assocation/European Association for the Study of Diabetes (ADA/EASD) and American Association of Clinical Endocrinologists (AACE) recommendations, ${ }^{11,12} \sim 50 \%$ of patients with T2D fail to achieve adequate glycemic control (glycated hemoglobin [HbA1c] $<7 \%$ ). ${ }^{13,14}$ Using data from the National Health and Nutrition Examination Survey, targets for glycemic
Correspondence: William H Polonsky Behavioral Diabetes Institute,

PO Box 2148, Del Mar, CA 92014, USA

Tel +l 7605255256

Emailwhp@behavioraldiabetes.org 


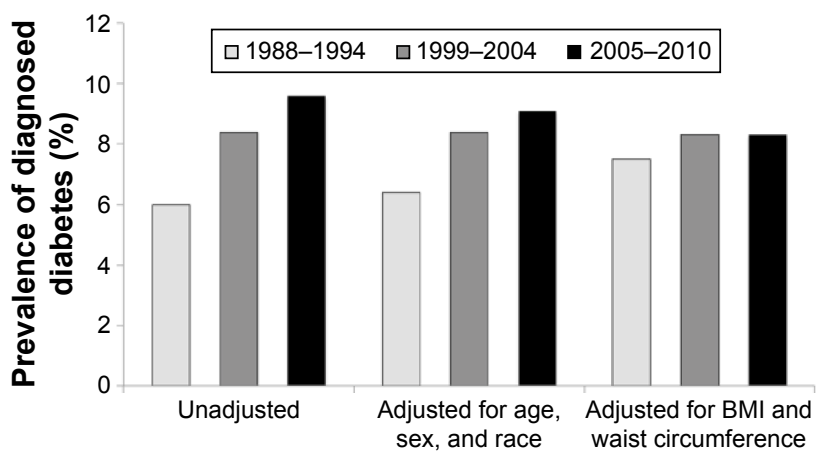

Figure I Prevalence of diagnosed diabetes among adults $\geq 20$ years old from the NHANES of 1988-1994 and 1999-2010.

Note: Data from a previous study. ${ }^{4}$

Abbreviations: NHANES, National Health and Nutrition Examination Survey; BMI, body mass index.

control (HbA1c) were achieved by only $55.5 \%$ of participants during 2009-2010. ${ }^{15}$ A number of factors contribute to poor glycemic control, including lack of integrated care in many health care systems, clinical inertia among health care providers, and poor patient adherence to self-care recommendations. Among them, it is evident that poor medication adherence looms large. ${ }^{16}$ This article reviewed the magnitude of the problem of poor medication adherence, the impact of poor adherence on long-term outcomes and health care costs, and the key contributors to poor medication adherence. In addition, the barriers and challenges that patients with $\mathrm{T} 2 \mathrm{D}$ and their health care providers face regarding medication adherence are reviewed and the potential future approaches for enhancing long-term adherence and persistence are highlighted.

\section{Scope of the problem}

Much of the evidence regarding poor medication adherence in diabetes is based on retrospective or observational studies that collect data from claim databases using a broad range of definitions. Consequently, the reported incidence of poor medication adherence in patients with T2D ranged widely from $38 \%$ to $93 \%$ owing to widely different methodological approaches. ${ }^{17-19}$ For the purposes of this article, we focused on one of the more common metrics and definitions of acceptable medication adherence, eg, a medication possession ratio (MPR) of $\geq 80 \%$ over the period of observation. ${ }^{20}$ A review of studies found that among patients with diabetes, hypertension, and dyslipidemia, only $59 \%$ had MPR $\geq 80 \% .{ }^{17}$ An analysis of 238,000 patients with T2D from the MarketScan database reported adherence rates (MPR $\geq 80 \%$ ) of $47.3 \%$ with dipeptidyl peptidase- 4 inhibitors, $41.2 \%$ with sulfonylureas, and $36.7 \%$ with thiazolidinediones (Figure 2). ${ }^{18}$ Similarly, a recent meta-analysis of 40 studies in which patients taking oral antidiabetic drugs found that medication adherence

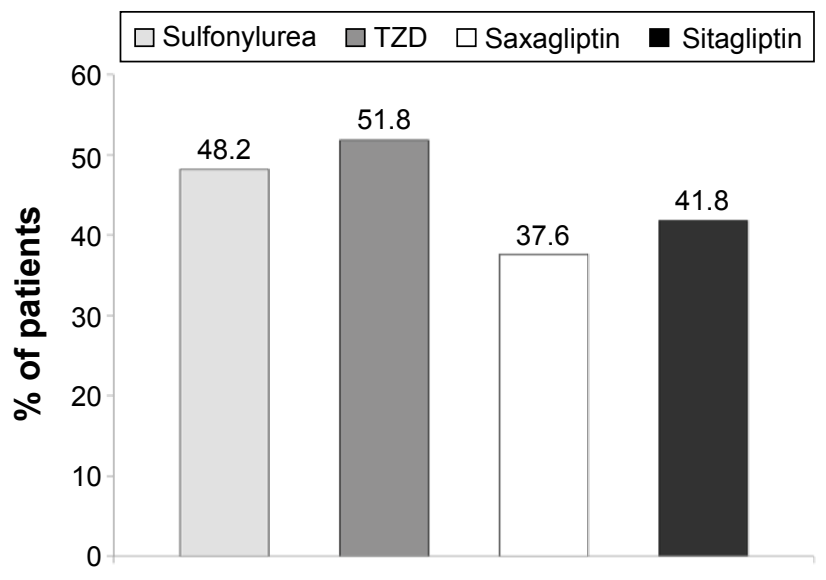

Figure 2 Percentage of patients discontinuing therapy ( $>60$ days without drug) with oral hypoglycemic drugs during a I-year follow-up of patients initiating therapy. Note: Data from a previous study. ${ }^{18}$

Abbreviation: TZD, thiazolidinedione.

rates were suboptimal, with only $67.9 \%$ of patients having an $\mathrm{MPR} \geq 80 \%$. $^{21}$

Another commonly used metric is medication persistence. Unfortunately, definitions vary even more widely here. Persistence is often defined as no gap in prescription drug supply for at least 30 days, although in some studies the definition is extended to $\geq 60-90$ days. Other researchers have defined persistence on the basis of the proportion of patients who discontinue treatment, which may include discontinuation for lack of efficacy, side effects, patient preferences, and other causes. In total, the body of current findings can be difficult to interpret. In one recent meta-analysis that included randomized clinical trials of patients with T2D, persistence rates ranged from $41 \%$ to $81 \%$ and discontinuation rates ranged from $10 \%$ to $61 \%$ over a 12 -month follow-up. ${ }^{21}$ According to the MarketScan database, $47 \%$ of 238,000 patients discontinued therapy (last day of drug prior to a 60 -day gap) over a 1 -year follow-up. ${ }^{18}$ A retrospective study of 1,321 patients with T2D treated with liraglutide (Novo Nordisk A/S, Bagsværd, Denmark) reported that 60\% were persistent with therapy (no 90-day gap) over a 12-month period, but only $34 \%$ were adherent (MPR $\geq 80 \%$ ). ${ }^{22}$ Among 40,000 patients with T2D, persistence (no $\geq 30$-day gap) over a 12 -month follow-up ranged from $27 \%$ to $32 \%{ }^{23}$ A retrospective analysis of persistence (time to discontinuation prior to $\geq 60$-day gap) with different oral or noninsulin injectable agents for T2D reported an overall discontinuation rate of $52.2 \%$ over 12 months. $^{24}$

In total, despite the wide range of definitions, there is relatively broad agreement across studies that problematic medication adherence and/or persistence is far from uncommon in T2D and may affect at least half of the population, if not more. 
Of note, however, most of the studies cited above are limited, given the nature of claim databases, to those patients who had at least an initial prescription filled for the new medication. The risk of poor medication adherence may be higher once consideration is given to those who fail to fill a first prescription. In one study that tracked new prescriptions written electronically over a 12 -month period for $>75,000$ patients, $31.4 \%$ of new prescriptions for diabetes drugs were never filled. ${ }^{25}$ This problem, often referred to as primary nonadherence, may be particularly relevant among patients who are refusing to initiate insulin or other injectable hypoglycemic therapy, typically due to injection phobia, inconvenience, poor patient-physician communication, and/or negative patient perceptions. ${ }^{26}$

\section{Consequences of poor medication adherence}

Poor adherence is associated with inadequate glycemic control, increased use of health care resources, higher medical costs, and markedly higher mortality rates. ${ }^{16,27,28}$ Among $>11,000$ veterans with T2D who were followed up for at least 5 years, poor medication adherence (MPR $<80 \%$ ) was significantly $(P<0.001)$ associated with poor glycemic control (HbA1c $>8 \%){ }^{16}$ The National Health and Wellness Survey of 1,198 patients with T2D found that each 1-point drop in self-reported medication adherence (using the Morisky Medication Adherence Scale) was associated with $0.21 \%$ increase in $\mathrm{HbA} 1 \mathrm{c}$, as well as $4.6 \%, 20.4 \%$, and $20.9 \%$ increase in physician, emergency room (ER), and hospital visits, respectively. ${ }^{28}$

Most importantly, poor medication adherence in T2D has also been linked to increased mortality. For example, among 15,984 patients from general practices in the UK who were treated with an oral antidiabetic agent, poor medication adherence and missed clinical appointments were each independently associated with a significant $(P<0.001)$ 1.6-fold increase in all-cause mortality. ${ }^{7}$ Similarly, Ho et al ${ }^{8}$ reported a significant association between poor medication adherence in T2D and all-cause mortality over time (odds ratio $1.8 ; P<0.001)$.

Finally, poor medication adherence results in increased costs of T2D outpatient care, ER visits, hospitalization, and managing T2D complications. ${ }^{6,29}$ An analysis of adherence to medications used to treat diabetes, dyslipidemia, and hypertension estimated that the direct cost of poor adherence was $\$ 105.8$ billion in 2010 across 230 million patients, which represented $\$ 453$ per adult. ${ }^{6}$ The pharmacy and administrative claim databases of CVS Caremark were used to assess the impact of medication adherence on hospital days, ER visits, and outpatient visits. ${ }^{29}$ The annual medical spending per patient with diabetes was projected to decrease by $\$ 4,413$ for all adults and by $\$ 5,170$ for those at the age of 65 years or older when MPR was $\geq 80 \%$. A systematic review of the economic impact of medication adherence and/or persistence on the overall cost of T2D care found that the average total annual cost per patient ranged from $\$ 4,570$ to $\$ 17,338$, and medication adherence was inversely associated with total health care and hospitalization costs. ${ }^{30}$

Improved medication adherence has the potential to significantly impact T2D health care costs. Patients with T2D who evidenced an improvement in medication adherence had a $13 \%$ reduction in the risk of hospitalization or ER visits, while a $15 \%$ increase in hospitalization and ER visits was associated with worsening adherence over time. ${ }^{31}$ Based on this analysis, improved adherence was projected to save $\$ 4.7$ billion annually, while reduced incidence of poor adherence was projected to save $\$ 3.6$ billion annually. Egede et $\mathrm{al}^{27}$ compared a large group of poorly adherent Veterans Administration(VA) patients (5-year MPR of 58\%) with a similar large group of adherent VA patients (5-year MPR of 93\%) and found that the poorly adherent group had a $37 \%$ lower pharmacy cost and a $7 \%$ lower outpatient cost over the 5-year period (likely associated with a decreased use of health care resources), but the inpatient cost was $41 \%$ higher. Annual cost savings in the range of \$661 million-\$1.16 billion were projected in the VA system by improving adherence in the poorly adherent group.

In total, it is apparent that addressing problematic medication adherence in the T2D population offers the potential for dramatically reducing costs and improving care and outcomes for patients.

\section{Key contributors to poor medication adherence}

Studies based on large claim databases have identified key demographic factors, such as younger age, lower education level, and lower income, that are associated with poor medication adherence in $\mathrm{T} 2 \mathrm{D},{ }^{24,32}$ but it may be of greater importance to identify those critical factors that are potentially modifiable. In total, the available body of data points to six key factors: perceived treatment efficacy, hypoglycemia, treatment complexity and convenience, cost of treatment, medication beliefs, and physician trust. It should be noted that many additional factors have been described in the extant literature (eg, depression, forgetfulness, and limited diabetes knowledge), but we suggest that it is these six factors that may be the most critical as well as the most amenable to change:

1. Perceived treatment efficacy: Patients are more likely to be adherent to medication regimens when they have 
some tangible sense that the prescribed medication is contributing to some positive and relatively immediate outcomes. ${ }^{33}$ Indeed, in numerous studies across a wide variety of chronic illness conditions, there is a consistent finding that medication adherence is associated with perceived need. ${ }^{34}$ The more firmly the patients believe that the prescribed medication is actually necessary, the more adherent they are likely to be. Consider, for example, that among 477 patients with T2D starting on any new class of diabetes medication, self-reported medication adherence over 6 months was associated with greater weight loss ( $\geq 3 \mathrm{~kg}$ : $29.9 \%$ adherent vs $24.2 \%$ poorly adherent) and with a greater likelihood of attaining HbA1c goal ( $<7.0 \%$ : $47.5 \%$ adherent vs $32.7 \%$ poorly adherent). ${ }^{35}$ These data may suggest that realization of patients that improvement is occurring (and that this may be due, at least to some extent, to their medications) contributes to their willingness to continue with their medications in a more reliable manner.

2. Hypoglycemia: A cross-sectional study of patients with T2D treated with metformin and a sulfonylurea agent found that patients reporting moderate or worse symptoms of hypoglycemia had poorer medication adherence vs those with no or mild hypoglycemia (MPR $>80 \%$ : $46 \%$ vs $67 \%, P<0.01) .{ }^{36}$ Among T2D participants in a recent survey, 56\% had experienced hypoglycemia and had higher HbA1c levels than in those with no reported hypoglycemia (Figure 3). ${ }^{37}$ Finally, a claims database was used to evaluate the impact of hypoglycemiarelated events on costs and discontinuation rates among 212,000 patients with T2D. ${ }^{38}$ During a 6-month interval,

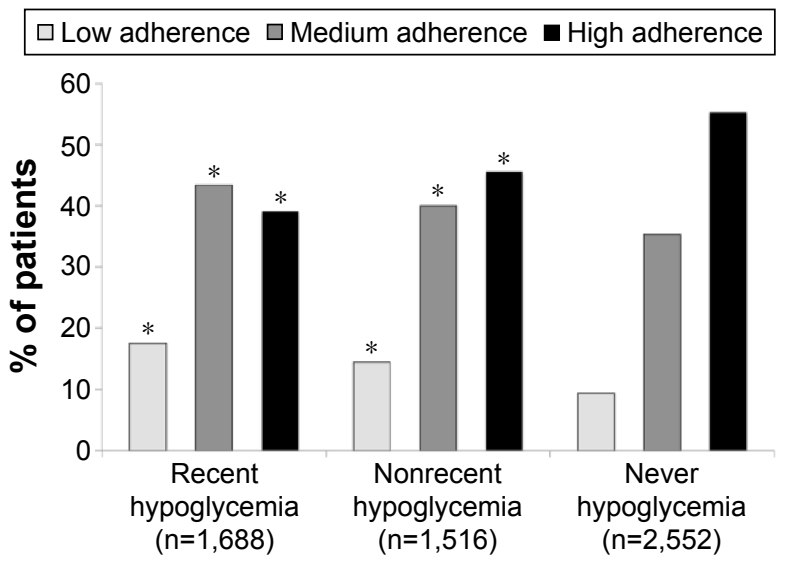

Figure 3 Percentage of patients with low, medium, or high adherence to antidiabetic medication based on the MMAS score according to the occurrence of recent hypoglycemic episodes.

Notes: ${ }^{*} P<0.05$ vs never hypoglycemia. Data from a previous study. ${ }^{37}$ Abbreviation: MMAS, Morisky Medication Adherence Scale. the risk for medication discontinuation was significantly $(P<0.0001)$ greater among those with a hypoglycemic event vs those with no reported hypoglycemia. It is noteworthy that even a single hypoglycemic event may contribute to greater fear of hypoglycemia in patients with $\mathrm{T} 2 \mathrm{D},{ }^{39}$ and hypoglycemic fear, in turn, may contribute to poorer medication adherence as the patient chooses to keep his/her blood glucose levels in a higher range where further hypoglycemic events will be less likely. ${ }^{40}$ The choice of medication(s) will, of course, have a major impact on the risk of hypoglycemia. However, even in the case of sulfonylureas, the actual likelihood of hypoglycemic problems may be influenced by the dosage prescribed, prescription errors, and/or how well or poorly the patient understands and follows medication directions.

3. Treatment complexity and convenience: Not surprisingly, medication adherence and persistence become more challenging when the treatment itself is perceived as more difficult, onerous, or burdensome. ${ }^{41}$ In their comprehensive review of 76 studies, Claxton et $\mathrm{al}^{42}$ found that the prescribed number of doses per day was inversely associated with medication adherence; indeed, the mean adherence across studies decreased progressively from $79 \%$ with a once-daily dose to $51 \%$ with a four times daily dose. Several recent reviews have confirmed these findings, with adherence rates for patients with chronic diseases, including T2D, found to be significantly lower for any medication regimen requiring more than once-daily dosing (79\%-94\% once daily vs 38\%-67\% three times daily; $P<0.05) .{ }^{43,44}$ Beyond the influence of dosing schedules, recent data suggest that the overall complexity of the $\mathrm{T} 2 \mathrm{D}$ medication regimen predicts adherence, with greater complexity contributing to poorer adherence. ${ }^{45}$ Similarly, the convenience or complexity of medication delivery devices can influence adherence. For example, in retrospective analyses of insulin pen vs vial and syringe use in T2D samples, improved persistence and adherence, improved glycemic control, and lower rates of hypoglycemia were reported in the insulin pen groups. $^{46-49}$

4. Cost of treatment. Out-of-pocket costs for medications have been consistently associated with problematic adherence across treatment conditions. ${ }^{50}$ Higher outof-pocket costs for antidiabetic medications in particular are linked to poorer adherence. ${ }^{32,51}$ To illustrate, patients with T2D receiving a low-income subsidy for Medicare Part D were found to have lower out-of-pocket costs and 
better medication adherence than those not receiving the subsidy. ${ }^{52}$

5. Medication beliefs: Many patients hold markedly negative or highly skeptical beliefs about their prescribed medications, often fearing that the long-term risks outweigh any likely benefits. ${ }^{26,53}$ Numerous studies have examined the impact of this "necessity-concerns framework"; although - as noted above - while believing that one's medications are necessary is associated with adherence, there is a consistent finding across the studies to date that patients' concerns about their medications are more strongly linked to adherence than their beliefs in the necessity of those same medications. ${ }^{54}$ In patients with T2D, such concerns about the possible negative impact of medications are associated with poor adherence ${ }^{55}$ as well as reluctance to initiate new medications, both orals ${ }^{56}$ as well as injectables. ${ }^{57,58}$

6. Physician trust: Adherence to hypoglycemic medications ${ }^{59}$ as well as antidepressant medications ${ }^{60}$ has been linked to patients' trust in their physicians. In a conceptually similar vein, Kerse et $\mathrm{al}^{61}$ found that primary care patients' sense of "concordance" with their physician (feeling that their needs during medical visits had been heard and addressed) predicted medication adherence over time. In a large multinational survey, Polonsky et $\mathrm{al}^{62}$ found that ratings of patients with $\mathrm{T} 2 \mathrm{D}$ on the overall quality of communication with their physicians at the time of diagnosis were linked to adherence to current hypoglycemic medications. To highlight the potential influence of physician trust, a small study by Piette et $\mathrm{al}^{63}$ reported that the association between medication adherence and out-of-pocket costs is minimized among those patients who report high trust in their physicians.

Of note, while the available data focus solely on the critical value of trust in the physicians, it seems likely that trust in other key health care professionals with whom the patients have ongoing contact may also be similarly potent in influencing medication attitudes and behaviors. Therefore, we hope to see future research examining how medication adherence is affected, for example, by trust in community pharmacists (whose clinical practice role in the US has been expanding in the recent years) and trust in nurse specialists in the UK (who play a central role in the diabetes care system of National Health Service). In summary, these data suggest that modifiable factors influencing T2D medication adherence fall into two broad categories: treatment burden (eg, complexity and convenience, out-of-pocket costs, and hypoglycemia risk) and treatment-related beliefs (eg, perceived treatment efficacy, medication beliefs, and trust in one's health care providers). To address problematic adherence, it would therefore seem likely that effective strategies might target one or both of these domains. However, what is known about what really works?

\section{Interventions to address poor medication adherence}

While numerous methods to address poor medication adherence across disease states have been developed and tested, including educational programs, disease management programs, intensive behavioral support, medication reminders, and special packaging, long-term, sustained reductions in the rates of poor adherence have been difficult to achieve. ${ }^{64,65}$ Recent literature reviews focusing specifically on T2D-specific medication adherence interventions have led to similarly disappointing conclusions; in those cases where benefits are apparent, the magnitude of intervention effects is typically small and/or of limited duration. ${ }^{66-70}$ A closer examination of the wide variety of intervention contents revealed no single form of intervention to be consistently effective for improving adherence, ${ }^{71}$ though multifaceted interventions were found to be more effective than single-strategy approaches, ${ }^{66}$ and as observed in one recent review, interventions targeting medication side effects might be of particular value. ${ }^{67}$

Descriptions of the specific T2D interventions are often inexact, making it difficult to determine which of the key modifiable factors, if any, are being targeted. For example, educational and/or behavioral support interventions are described as central pillars in the majority of adherence interventions, especially in the complex interventions consisting of multiple strategies, but exactly how these operate or what obstacles are being targeted are typically not specified.

In total, we speculate that most interventions to date have focused within the broad category of reducing treatment burden - focusing primarily on the problem of medication behavior rather than medication attitudes. Indeed, we know of no study that has directly examined the potential impact of addressing dysfunctional medical beliefs, perceived treatment efficacy, or any other aspect of patients' treatment-related beliefs. One of the keys to future advances in addressing problematic medication adherence, especially primary medication adherence, may be through better physician communication regarding benefits and risks of treatment, addressing patients' treatment concerns, engaging in shared decision-making, and providing and/or supporting selfmanagement training. ${ }^{26}$ 
Finally, it must be noted that the inability to draw firm conclusions regarding interventions is partly, perhaps largely, due to methodological limitations. To date, measures of adherence across studies vary widely, hard outcomes (eg, changes in glycemic control) are often lacking, interventions may not be clearly explained, and duration of follow-up is often inadequate. ${ }^{70}$ Research into the causes and management of medication adherence will require improved study designs that can explore the feasibility of long-term interventions, development of more objective adherence measures, and the inclusion of sufficient numbers of patients to detect improvements in clinical outcomes. ${ }^{65}$ A key element is the need for greater consistency when measuring medication adherence, which require better instruments and tools for assessment. ${ }^{20}$

\section{Future developments}

Novel treatment approaches are in development that may address many of the treatment burden factors (eg, treatment complexity, hypoglycemia, and side effects) as well as treatment belief factors (eg, perceived treatment efficacy). While drugs that are administered daily or even weekly for T2D have not shown substantial benefits with respect to improved adherence and persistence, new products will soon become available that are administered at monthly or longer intervals, potentially addressing some of the barriers to maintaining good medication adherence. One approach is sustained delivery of a therapeutic agent that has demonstrated efficacy, safety, and improved outcomes. Optimally, for treatment of diabetes, this agent should deliver sustained reduction in HbA1c levels, result in weight loss, and have a favorable side-effect profile to minimize the chance of discontinuation. One such product, ITCA 650 (Intarcia Therapeutics, Inc., Boston, MA, USA), provides continuous delivery of exenatide for up to 1 year via a subcutaneous osmotic mini pump. Phase III trials in patients with T2D have shown robust efficacy, tolerability consistent with the glucagon-like peptide- 1 class, and $100 \%$ adherence. ${ }^{72,73}$

In addition, drug combinations may provide another valuable approach by simplifying the dosage regimen with fixed-dose formulations. A retrospective analysis of patients with T2D taking fixed-dose combinations versus individual dose combinations showed significantly $(P<0.001)$ greater adherence ( $57.0 \%$ vs $50.7 \%$ ) and persistence (32\% vs $27 \%$ ) with the fixed-dose combination. ${ }^{23}$ A number of fixed-dose combinations of oral antidiabetic agents and insulin formulations are now available, and recently, insulin degludec combined with liraglutide was approved in Europe and is pending for approval in the US. A number of other combinations of oral and injectable antidiabetic agents are either approved or in late-stage clinical development (ClinicalTrials.gov). However, the benefit-risk ratio of fixed-dose combinations needs to be demonstrated, and to date, little evidence is available to demonstrate improvements in adherence with these or other combinations.

In total, by providing new approaches that can make the process of taking medication less burdensome (or, as in the case of ITCA 650, even less apparent or noticeable) while simultaneously providing favorable outcomes (especially, long-term glycemic control and weight loss), there is a likelihood that patients may begin to weigh the hassles/risks of medications vs the benefits quite differently, leading to a greater sense of perceived treatment efficacy and an enhanced sense of engagement with their own diabetes selfmanagement. ${ }^{33}$

\section{Summary and conclusion}

Medication adherence in T2D remains poor despite the availability of many new classes of medications and increased efforts toward patient education and targeted interventions that address adherence. New nonpharmacologic and pharmacologic approaches are needed that will have a clinically significant and sustained long-term impact on adherence. Innovative strategies for addressing treatment burden as well as patients' problematic beliefs about their medications are needed. Toward this end, novel drugs or delivery systems that remove the need for daily, weekly, or even monthly dosing should be available in the near future, offering the potential for greatly increased adherence accompanied by markedly improved glycemic control, reduced complications of diabetes, and lower health care costs and resource use.

\section{Acknowledgment}

The authors would like to acknowledge the editorial assistance of Richard S Perry, PharmD, in the preparation of this manuscript, which was supported by Intarcia Therapeutics, Inc., Boston, MA, USA.

\section{Disclosure}

Doctor Polonsky has received grant support or served as a consultant to Eli Lilly \& Company, Novo Nordisk, Sanofi, Dexcom, Roche, Abbott, Johnson \& Johnson, AstraZeneca, Merck, Boehringer Ingelheim, and Intarcia Therapeutics, Inc. Doctor Henry has received grants or research support from Hitachi, Eli Lilly \& Company, and ViaCyte. He has also served as a consultant or advisory 
board member of Alere; AstraZeneca; Boehringer Ingelheim; Elcelyx; Intarcia Therapeutics, Inc.; Ionis Pharmaceuticals; Johnson \& Johnson/Janssen Pharmaceuticals; Novo Nordisk Pharmaceuticals; and Sanofi-Aventis. The authors report no other conflicts of interest in this work.

\section{References}

1. International Diabetes Federation [webpage on the Internet]. IDF Diabetes Atlas, Sixth Edition; 2014. Available from: www.idf.org/ sites/default/files/EN_6E_Atlas_Full_0.pdf. Accessed April 7, 2015.

2. Centers for Disease Control and Prevention. National Diabetes Statistics Report: Estimates of Diabetes and its Burden in the United States; 2014. Available from: https://www.cdc.gov/diabetes/.../statsreport14/ national-diabetes-report-web.pdf. Accessed April 7, 2015.

3. Cheng YJ, Imperatore G, Geiss LS, et al. Secular changes in the agespecific prevalence of diabetes among US adults: 1988-2010. Diabetes Care. 2013;36(9):2690-2696.

4. Selvin E, Parrinello CM, Sacks DB, Coresh J. Trends in prevalence and control of diabetes in the United States, 1988-1994 and 1999-2010. Ann Intern Med. 2014;160(8):517-525.

5. Dall TM, Yang W, Halder P, et al. The economic burden of elevated blood glucose levels in 2012: diagnosed and undiagnosed diabetes, gestational diabetes mellitus, and prediabetes. Diabetes Care. 2014; 37(12):3172-3179.

6. Nasseh K, Frazee SG, Visaria J, Vlahiotis A, Tian Y. Cost of medication nonadherence associated with diabetes, hypertension, and dyslipidemia. Am J Pharm Benefits. 2012;4(2):e41-e47.

7. Currie CJ, Peyrot M, Morgan CL, et al. The impact of treatment noncompliance on mortality in people with type 2 diabetes. Diabetes Care. 2012; 35(6):1279-1284.

8. Ho PM, Rumsfeld JS, Masoudi FA, et al. Effect of medication nonadherence on hospitalization and mortality among patients with diabetes mellitus. Arch Intern Med. 2006;166(17):1836-1841.

9. Lind M, Garcia-Rodriguez LA, Booth GL, et al. Mortality trends in patients with and without diabetes in Ontario, Canada and the UK from 1996 to 2009: a population-based study. Diabetologia. 2013;56(12):2601-2608.

10. Seuring T, Archangelidi O, Suhrcke M. The economic costs of type 2 diabetes: a global systematic review. Pharmacoeconomics. 2015;33(8): 811-831.

11. Handelsman Y, Bloomgarden ZT, Grunberger G, et al. American association of clinical endocrinologists and American college of endocrinology-clinical practice guidelines for developing a diabetes mellitus comprehensive care plan - 2015. Endocr Pract. 2015;21(suppl 1):1-87.

12. Inzucchi SE, Bergenstal RM, Buse JB, et al. Management of hyperglycemia in type 2 diabetes, 2015: a patient-centered approach: update to a position statement of the American Diabetes Association and the European Association for the study of diabetes. Diabetes Care. 2015; 38(1):140-149.

13. Ali MK, McKeever Bullard K, Imperatore G, et al; Centers for Disease Control and Prevention (CDC). Characteristics associated with poor glycemic control among adults with self-reported diagnosed diabetes National Health and Nutrition Examination Survey, United States, 2007-2010. MMWR Morb Mortal Wkly Rep. 2012;61(suppl):32-37.

14. Ford ES. Trends in the control of risk factors for cardiovascular disease among adults with diagnosed diabetes: findings from the National Health and Nutrition Examination Survey 1999-2008. J Diabetes. 2011; 3(4):337-347.

15. Wong ND, Patao C, Wong K, Malik S, Franklin SS, Iloeje U. Trends in control of cardiovascular risk factors among US adults with type 2 diabetes from 1999 to 2010: comparison by prevalent cardiovascular disease status. Diab Vasc Dis Res. 2013;10(6):505-513.

16. Egede LE, Gebregziabher M, Echols C, Lynch CP. Longitudinal effects of medication nonadherence on glycemic control. Ann Pharmacother 2014;48(5):562-570.
17. Cramer JA, Benedict A, Muszbek N, Keskinaslan A, Khan ZM. The significance of compliance and persistence in the treatment of diabetes, hypertension and dyslipidaemia: a review. Int J Clin Pract. 2008; 62(1):76-87.

18. Farr AM, Sheehan JJ, Curkendall SM, Smith DM, Johnston SS, Kalsekar I. Retrospective analysis of long-term adherence to and persistence with DPP-4 inhibitors in US adults with type 2 diabetes mellitus. Adv Ther. 2014;31(12):1287-1305.

19. Krass I, Schieback P, Dhippayom T. Adherence to diabetes medication: a systematic review. Diabet Med. 2015;32(6):725-737.

20. Clifford S, Perez-Nieves M, Skalicky AM, Reaney M, Coyne KS. A systematic literature review of methodologies used to assess medication adherence in patients with diabetes. Curr Med Res Opin. 2014;30(6): 1071-1085.

21. Iglay K, Cartier SE, Rosen VM, et al. Meta-analysis of studies examining medication adherence, persistence, and discontinuation of oral antihyperglycemic agents in type 2 diabetes. Curr Med Res Opin. 2015; 31(7):1283-1296

22. Buysman EK, Liu F, Hammer M, Langer J. Impact of medication adherence and persistence on clinical and economic outcomes in patients with type 2 diabetes treated with liraglutide: a retrospective cohort study. Adv Ther. 2015;32(4):341-355.

23. Lokhandwala T, Smith N, Sternhufvud C, Sörstadius E, Lee WC, Mukherjee J. A retrospective study of persistence, adherence, and health economic outcomes of fixed-dose combination versus loosedose combination of oral anti-diabetes drugs. J Med Econ. 2016;19(3): 203-212.

24. Curkendall SM, Thomas N, Bell KF, Juneau PL, Weiss AJ. Predictors of medication adherence in patients with type 2 diabetes mellitus. Curr Med Res Opin. 2013;29(10):1275-1286.

25. Fischer MA, Stedman MR, Lii J, et al. Primary medication non-adherence: analysis of 195,930 electronic prescriptions. J Gen Intern Med. 2010; 25(4):284-290.

26. Karter AJ, Subramanian U, Saha C, et al. Barriers to insulin initiation: the translating research into action for diabetes insulin starts project. Diabetes Care. 2010;33(4):733-735.

27. Egede LE, Gebregziabher M, Dismuke CE, et al. Medication nonadherence in diabetes: longitudinal effects on costs and potential cost savings from improvement. Diabetes Care. 2012;35(12):2533-2539.

28. DiBonaventura M, Wintfeld N, Huang J, Goren A. The association between nonadherence and glycated hemoglobin among type 2 diabetes patients using basal insulin analogs. Patient Prefer Adherence. 2014; 8:873-882.

29. Roebuck MC, Liberman JN, Gemmill-Toyama M, Brennan TA Medication adherence leads to lower health care use and costs despite increased drug spending. Health Aff (Millwood). 2011;30(1):91-99.

30. Breitscheidel L, Stamenitis S, Dippel FW, Schöffski O. Economic impact of compliance to treatment with antidiabetes medication in type 2 diabetes mellitus: a review paper. J Med Econ. 2010;13(1):8-15.

31. Jha AK, Aubert RE, Yao J, Teagarden JR, Epstein RS. Greater adherence to diabetes drugs is linked to less hospital use and could save nearly \$5 billion annually. Health Aff (Millwood). 2012;31(8):1836-1846.

32. Kirkman MS, Rowan-Martin MT, Levin R, et al. Determinants of adherence to diabetes medications: findings from a large pharmacy claims database. Diabetes Care. 2015;38(4):604-609.

33. Polonsky WH, Skinner TC. Perceived treatment efficacy: an overlooked opportunity in diabetes care. Clin Diabetes. 2010;28(2):89-92.

34. Gadkari AS, McHorney CA. Medication nonfulfillment rates and reasons: narrative systematic review. Curr Med Res Opin. 2010;26(3): 683-705.

35. McAdam-Marx C, Bellows BK, Unni S, et al. Determinants of glycaemic control in a practice setting: the role of weight loss and treatment adherence (the DELTA study). Int J Clin Pract. 2014;68(11):1309-1317.

36. Walz L, Pettersson B, Rosenqvist U, Deleskog A, Journath G, Wändell P. Impact of symptomatic hypoglycemia on medication adherence, patient satisfaction with treatment, and glycemic control in patients with type 2 diabetes. Patient Prefer Adherence. 2014;8:593-601. 
37. Lopez JM, Annunziata K, Bailey RA, Rupnow MF, Morisky DE. Impact of hypoglycemia on patients with type 2 diabetes mellitus and their quality of life, work productivity, and medication adherence. Patient Prefer Adherence. 2014;8:683-692.

38. Bron M, Marynchenko M, Yang H, Yu AP, Wu EQ. Hypoglycemia, treatment discontinuation, and costs in patients with type 2 diabetes mellitus on oral antidiabetic drugs. Postgrad Med. 2012;124(1):124-132.

39. Hajós TR, Polonsky WH, Pouwer F, Gonder-Frederick L, Snoek FJ. Toward defining a cutoff score for elevated fear of hypoglycemia on the hypoglycemia fear survey worry subscale in patients with type 2 diabetes. Diabetes Care. 2014;37(1):102-108.

40. Gonder-Frederick LA, Vajda KA, Schmidt KM, et al. Examining the behaviour subscale of the hypoglycaemia fear survey: an international study. Diabet Med. 2013;30(5):603-609.

41. Garcia-Pérez LE, Alvarez M, Dilla T, Gil-Guillén V, Orozco-Beltrán D. Adherence to therapies in patients with type 2 diabetes. Diabetes Ther. 2013;4(2):175-194.

42. Claxton AJ, Cramer J, Pierce C. A systematic review of the associations between dose regimens and medication compliance. Clin Ther. 2001; 23(8):1296-1310.

43. Coleman CI, Limone B, Sobieraj DM, et al. Dosing frequency and medication adherence in chronic disease. J Manag Care Pharm. 2012;18(7): $527-539$.

44. Saini SD, Schoenfeld P, Kaulback K, Dubinsky MC. Effect of medication dosing frequency on adherence in chronic diseases. Am J Manag Care. 2009;15(6):e22-e33.

45. de Vries ST, Keers JC, Visser R, et al. Medication beliefs, treatment complexity, and non-adherence to different drug classes in patients with type 2 diabetes. J Psychosom Res. 2014;76(2):134-138.

46. Davis SN, Wei W, Garg S. Clinical impact of initiating insulin glargine therapy with disposable pen versus vial in patients with type 2 diabetes mellitus in a managed care setting. Endocr Pract. 2011;17(6):845-852.

47. Buysman E, Conner C, Aagren M, Bouchard J, Liu F. Adherence and persistence to a regimen of basal insulin in a pre-filled pen compared to vial/syringe in insulin-naïve patients with type 2 diabetes. Curr Med Res Opin. 2011;27(9):1709-1717.

48. Grabner M, Chu J, Raparla S, Quimbo R, Zhou S, Conoshenti J. Clinical and economic outcomes among patients with diabetes mellitus initiating insulin glargine pen versus vial. Postgrad Med. 2013;125(3): 204-213.

49. Xie L, Zhou S, Pinsky BW, Buysman EK, Baser O. Impact of initiating insulin glargine disposable pen versus vial/syringe on real-world glycemic outcomes and persistence among patients with type 2 diabetes mellitus in a large managed care plan: a claims database analysis. Diabetes Technol Ther. 2014;16(9):567-575.

50. Eaddy MT, Cook CL, O'Day K, Burch SP, Cantrell CR. How patient costsharing trends affect adherence and outcomes: a literature review. $P T$. 2012;37(1):45-55.

51. Piette JD, Heisler M, Wagner TH. Problems paying out-of-pocket medication costs among older adults with diabetes. Diabetes Care. 2004;27(2): 384-391.

52. Yala SM, Duru OK, Ettner SL, Turk N, Mangione CM, Brown AF. Patterns of prescription drug expenditures and medication adherence among medicare part $\mathrm{D}$ beneficiaries with and without the low-income supplement. BMC Health Serv Res. 2014;14:665.

53. Aikens JE, Piette JD. Diabetic patients' medication underuse, illness outcomes, and beliefs about antihyperglycemic and antihypertensive treatments. Diabetes Care. 2009;32(1):19-24.

54. Foot H, La Caze A, Gujral G, Cottrell N. The necessity-concerns framework predicts adherence to medication in multiple illness conditions: a meta-analysis. Patient Educ Couns. 2016;99(5):706-717.

55. Mann DM, Ponieman D, Leventhal H, Halm EA. Predictors of adherence to diabetes mediations: the role of disease and medication beliefs. J Behav Med. 2009;32(3):278-284.

56. Grant B, Colello SH. Culture change through patient engagement. Nurs Manage. 2010;41(10):44-46.
57. Polonsky WH, Fisher L, Guzman S, Villa-Caballero L, Edelman SV. Psychological insulin resistance in patients with type 2 diabetes: the scope of the problem. Diabetes Care. 2005;28(10):2543-2545.

58. Polonsky WH, Fisher L, Hessler D, Bruhn D, Best JH. Patient perspectives on once-weekly medications for diabetes. Diabetes Obes Metab. 2011;13(2):144-149.

59. Ratanawongsa N, Karter AJ, Parker MM, et al. Communication and medication adherence: the diabetes study of Northern California. JAMA Intern Med. 2013;173(3):201-208.

60. Bauer AM, Parker MM, Schillinger D, et al. Associations between antidepressant adherence and shared decision-making, patientprovider trust, and communication among adults with diabetes: diabetes study of Northern California (DISTANCE). J Gen Intern Med. 2014;29(8):1139-1147.

61. Kerse N, Buetow S, Mainous AG 3rd, Young G, Coster G, Arroll B. Physician-patient relationship and medication compliance: a primary care investigation. Ann Fam Med. 2004;2(5):455-461.

62. Polonsky WH, Fisher L, Hessler D, Edelman SV. What is so tough about self-monitoring of blood glucose? Perceived obstacles among patients with type 2 diabetes. Diabet Med. 2014;31(1):40-46.

63. Piette JD, Heisler M, Krein S, Kerr EA. The role of patient-physician trust in moderating medication nonadherence due to cost pressures. Arch Intern Med. 2005;165(15):1749-1755.

64. Demonceau J, Ruppar T, Kristanto P, et al; ABC project team. Identification and assessment of adherence-enhancing interventions in studies assessing medication adherence through electronically compiled drug dosing histories: a systematic literature review and meta-analysis. Drugs. 2013;73(6):545-562.

65. Nieuwlaat R, Wilczynski N, Navarro T, et al. Interventions for enhancing medication adherence. Cochrane Database Syst Rev. 2014;11: CD000011.

66. Sapkota S, Brien JA, Greenfield JR, Aslani P. A systematic review of interventions addressing adherence to anti-diabetic medications in patients with type 2 diabetes - components of interventions. PLoS One. 2015;10(6):e0128581.

67. Vignon Zomahoun HT, de Bruin M, Guillaumie L, et al. Effectiveness and content analysis of interventions to enhance oral antidiabetic drug adherence in adults with type 2 diabetes: systematic review and metaanalysis. Value Health. 2015;18(4):530-540.

68. Williams JL, Walker RJ, Smalls BL, Campbell JA, Egede LE. Effective interventions to improve medication adherence in type 2 diabetes: a systematic review. Diabetes Manag (Lond). 2014;4(1):29-48.

69. Zullig LL, Gellad WF, Moaddeb J, et al. Improving diabetes medication adherence: successful, scalable interventions. Patient Prefer Adherence. 2015;9:139-149.

70. Antoine SL, Pieper D, Mathes T, Eikermann M. Improving the adherence of type 2 diabetes mellitus patients with pharmacy care: a systematic review of randomized controlled trials. BMC Endocr Disord. 2014; $14: 53$.

71. Sapkota S, Brien JA, Greenfield J, Aslani P. A systematic review of interventions addressing adherence to anti-diabetic medications in patients with type 2 diabetes-impact on adherence. PLoS One. 2015; 10(2):e0118296.

72. Baron MA, Buse J, Azeem R, Kjems L, Rosenstock J. A randomised, double-blind, placebo-controlled, 39 week trial of ITCA 650 as add-on therapy in type 2 diabetes. Abstract 112 presented at the 51st Annual Meeting of the European Association for the Study of Diabetes; September 16, 2015; Stockholm, Sweden.

73. Henry RR, Rosenstock J, Denham DS, Prabhakar P, Kjems L, Baron MA. Efficacy and tolerability of 39 weeks of ITCA 650 (continuous subcutaneous exenatide) in poorly controlled T2DM with high baseline A1c ( $>10 \%)$. Abstract 1107-P presented at the 75th American Diabetes Association Scientific Sessions; June 6, 2015; San Diego, CA. 
Patient Preference and Adherence

Dovepress

\section{Publish your work in this journal}

Patient Preference and Adherence is an international, peer-reviewed, open access journal that focuses on the growing importance of patient preference and adherence throughout the therapeutic continuum. Patient satisfaction, acceptability, quality of life, compliance, persistence and their role in developing new therapeutic modalities and compounds to optimize

Submit your manuscript here: http://www.dovepress.com/patient-preference-and-adherence-journ clinical outcomes for existing disease states are major areas of interest for the journal. This journal has been accepted for indexing on PubMed Central. The manuscript management system is completely online and includes a very quick and fair peer-review system, which is all easy to use. Visit http://www. dovepress.com/testimonials.php to read real quotes from published authors. 